\title{
AC 2009-2303: KEEPING IN TOUCH WITH YOUR CLASS: SHORT CLASS EVALUATIONS
}

\section{Mary Anderson-Rowland, Arizona State University}

MARY R.ANDERSON-ROWLAND is the PI of an NSF grant to explore the feasibility of working with non-metropolitan community colleges to produce more engineers, especially female and underrepresented minority engineers. She also directs three academic scholarship programs, including one for transfer students. An Associate Professor in Industrial, Systems and Operations Engineering, she was the Associate Dean of Student affairs in the Ira a. Fulton School of Engineering at ASU from 1993-2004. She received the ASEE Minorities Award 2006, the SHPE Educator of the Year 2005, and won the National Engineering Award in 2003, the highest honor given by AAES. In 2002 she was named the Distinguished Engineering Educator by the Society of Women Engineers. Her awards are based on her mentoring of students, especially women and underrepresented minority students, and her research in the areas of recruitment and retention. A SWE and ASEE Fellow, she is a frequent speaker on career opportunities and diversity in engineering. 


\title{
Keeping in Touch with Your Class: Short Class Evaluations
}

\begin{abstract}
Especially for a beginning or fairly new professor, a primary concern of teaching is the preparation of proper material for each class session. This paper discusses a way to determine how well the students are learning the material, especially in quite large classes, as well as their opinions on the course. A search of the literature shows that the "Minute Manager" stands out as an easy and effective way to receive continuous feedback on the delivery of a course. This paper describes how the author has adapted the Minute Manager for use in her courses and program seminars.
\end{abstract}

The questions asked on the Minute Manager evaluation are: 1) What was the most important thing that you learned today? 2) What did you like most about the class today? 3) Do you have any questions about the class today? Are there topics that are muddy? 4) Do you have any questions about the course? and 5) Comments. At the bottom of the brightly colored half page, the student is asked to circle the overall rating of the class from $1=$ Excellent to $5=$ Very Poor.

The paper will discuss uses of the Minute Manager, the types of answers that can be expected, and the student impressions of their use in a junior-level statistics problem-solving class for engineers.

\section{Introduction}

Do you remember what it was like as you walked to your first class as a professor at a college or university? With a newly minted Ph.D., the professor walks to her first assigned class and is conscious that no one is watching and no one is checking to see what will be delivered in the lecture, let alone if the material delivered is correct. The professor is a bit aghast at the whole scenario, but then remembers that she has earned a Ph.D. degree. Because of this degree, the newly acquired faculty colleagues trust that a new professor is responsible, knows the material, and knows how to teach. Of course the new professor soon learns that no one has to be in the classroom to check on the teaching. If a professor, especially a new one, is not doing well in a course, the students immediately report problems to the department chair. However, the new professor feels OK about the class because she taught a few courses as a graduate teaching assistant. In those circumstances, the course syllabus was set and a graduate student was not individually responsible for preparing the tests, but the new professor did teach. So the new professor is prepared to teach. Or is she?

Whether a professor is new or seasoned, a primary concern is the effectiveness of her teaching. Are the students learning what they need to learn? The general class learning can be measured by quizzes and exams. Professors receive feedback from the students through the teaching evaluation at the end of the semester. It would be nice, however, for the professor to know how well she and the students are working together long before a final teaching evaluation. Even though the lectures may have been academically correct, it is possible that the professor may be 
surprised about what the students thought of the lectures or how much they understood. If possible, it would be nice to have no surprises in the student semester evaluations. It is possible to work with and get to know, quite easily, where the students are with respect to the class concepts throughout the semester, especially in quite large classes.

We should not be surprised that not all engineering professors are effective teachers. "College teaching may be the only skilled profession that neither presumes experience nor routinely provides training for its novice practitioners.... They have also had to teach themselves how to devise stimulating lectures and rigorous but fair assignments and tests, how to motivate students to learn and how to make them active participants in the learning process, and how to help them develop critical problem-solving, communication, and teamwork skills." "I Is there a better way? This paper will show that there is a simple way to work with and get to know where students are with respect to the class throughout the semester, even in large classes.

\section{Literature Review of Teaching Evaluations}

It should be clear that each professor should not have to reinvent the wheel by herself on how to be an effective teacher. Appropriate mentoring and the passing on of tips to become more effective in the classroom can make the learning process about teaching for a new professor much shorter and efficient. The literature shows that new faculty can easily become stressed which results in ineffective teaching and low scholarly productivity. ${ }^{1}$ In a large study Boice ${ }^{2}$ learned that most new faculty equate good teaching with correct content and use lecturing as the only way of instruction, equate their teaching with improving their lecture notes, spend up to 27 hours a week preparing for classes, put so much material into their lectures that they must rush to cover it all, leave little time for interaction and discussion with students, and teach defensively to avoid student complaints, but get low teaching evaluations anyway. Among the few new faculty that fared well, Boice ${ }^{2}$ noticed that they added excitement to the classroom by integrating their research into their lectures; taught at a slower pace, left more time for student questions and interactions; and limited course preparation time, when teaching courses for a second time or more, to less than 1.5 hours of preparation for each hour of class.

Based on this and additional research, the SUCCEED Coalition developed a model program designed to help new faculty in all aspects of their career, including effective teaching. ${ }^{1} \mathrm{~A}$ teaching mentorship is part of their program. Ideally, the mentor and the mentee would co-teach a course with the mentor taking the lead on the course at first. The mentor and mentee meet between class periods to plan and to discuss the teaching in the last class. The mentee slowly takes on the responsibilities of planning and teaching and making up and grading homework assignments and tests. The mentor discusses the class afterwards with the mentee. In turn the mentor can invite the mentee to sit in on his/her class or arrange for the mentee to observe other good teachers. The mentor can also share class materials, encourage active learning in the classroom, and let the mentee know about teaching seminars that may be available and materials about effective teaching. ${ }^{1}$

The SUCCEED Coalition training also mentions The Minute Manager published in 1993 . $^{3}$ With a few minutes to go in the class, the instructor stops the class and asks the students to answer two questions anonymously: "What was the main point in today's class?" "What was the muddiest point?" After the class, the professor goes over the responses and looks for trends in the muddy points. At the beginning of the next class the instructor talks about these muddy trends. A 
second in-class technique that can be used to improve teaching is to use short in-class team assignments ${ }^{4}$ (less than 5 minutes each) to break up the lecture and provide interaction for the students. A paper was published in 2001 by SUCCEED $^{5}$ describing the five day workshop they developed for new engineering faculty. Brent, Felder, and Rajala published an update and assessment of their New Faculty Orientation Workshop in $2006 .{ }^{6}$

A just-in-time learning system has been used that enhances learning in the classroom setting. Students need to complete a "Warm Up" exercise on the web before each class. ${ }^{7}$ These submissions are graded on effort, rather than for technical accuracy to encourage the students to maintain student motivation. This method is not distance learning, but an enhancer to the faceto-face regular class meetings. The advantage of this system is that it forces the students to read the material before class. Evaluations of this learning method show that most students like this system. Of course, this does not reduce teaching preparation time, but rather increases it while the faculty member develops appropriate warm up exercises for each class period. Using this learning system, the attrition in an introductory physics class has declined by over $40 \%$ and the number of students choosing physics as a major or minor has increased significantly. ${ }^{7}$

Active and cooperative learning (ACL) has been used for several years to improve engineering teaching and learning. By 2003, over 1,000 copies of a one-page overview of ACL had been distributed. A two-page version can be found at http://www.foundationcoalition.org/publications/brochures/ACL One Page Introduction_v18.p $\underline{\mathrm{df}}$. An additional resource is a website http://clte.asu.edu/active. ${ }^{8}$ Of course, learning to use active and cooperative learning takes some effort and time to develop. The short in-class team activity ${ }^{4}$ mentioned earlier is a good example of how to incorporate active learning with little preparation time. In 2003 another effort took place to enhance engineering teaching: "Ways of Knowing, Ways of Practice" was a pilot distance learning experience to help faculty with reflection and continuous improvement of learning, both for themselves and their students, plus other benefits. Twenty professors took part in the pilot. ${ }^{9}$ This seminar involved weekly on-line discussions and required a two to three hours per week commitment per participant.

Drexel University's Outcomes Experiment explored whether a monetary incentive to spend time on improving teaching skills would be sufficient for professors to work on self-improvement. This study was conducted in 2004 and even though the professors were offered $\$ 40 / \mathrm{hr}$, the data collected over 5 years showed that even with the financial incentive, the professors only reported $0.5 \%$ of a normal work week was devoted to improving teaching. ${ }^{10}$ Based on past studies the researcher expected more than four times this amount of time. Almost half of the professors in the study spent less than 20 minutes per month on teaching improvement activities. A message from this study is that even with a financial incentive, faculty are not likely to spend very much time improving their teaching. The faculty reported that competing time demands simply did not allow for much time to be spent on improving teaching. It would seem then that teaching improvement activities that are quick and easy to learn and quick and easy to apply may have the best chance of being adopted by an engineering faculty member.

Concept inventories to measure engineering students' understanding of difficult concepts can determine which concepts are the most misunderstood by the students. After determining these concepts, the professor can then spend more time on these concepts and design additional exercises to drive home the correct concepts. ${ }^{11}$ 
Many papers have been written giving advice to new professors. ${ }^{12,13}$ Determining the learning styles of the student in any particular class can help the instructor know how to present the material that will be most easily understood by the class. ${ }^{14,15}$ Aghayere $^{16,17,18}$ uses a technique $^{\text {Agech }}$ for the continuous assessment of student learning that involves measuring students' perception of learning of course topics. The results of the data that he has collected in classes using his technique showed an increase in student learning and, at the same time, forced the students to reflect on and take charge of their own learning. Another way of assessing students in a class is that three times during the semester, evenly spaced, an outcomes assessment survey is completed by the students. ${ }^{19}$ To evaluate methods to improve teaching in engineering, faculty in one large university were randomly assigned to one of four separate cohorts (each receiving a different type of feedback designed to improve teaching). ${ }^{20}$ The results were that the feedback and follow-up consultation may have the most positive impact on student ratings of teaching. In this process, an instructional consultant facilitated a student feedback session at midterm and then conducted a follow-up consultation with the faculty member. However, videotaping the instructor and then following up with a consultation also had a positive impact on student ratings. Other papers related to advice for new engineering faculty such as that written by Jugdev ${ }^{21}$ give general advice on mentoring and tricks of the trade. Along the line of concept inventory, others have done work on discovering the misunderstandings of students in particular courses. ${ }^{22}$

In reviewing the literature on ways for instructors to easily receive continuous feedback during the delivery of a course, the Minute Manager seems to stand alone as a very easy and effective method. In this paper the author will present how she uses a version of the Minute Manager in her classes, a habit that she has used for many years.

\section{The Evaluation Form and Its Purpose}

The author has developed a "Minute Manager" form that covers a half sheet of paper as shown in Figure 1, usually printed on a tangerine, light green, or soft aqua colored paper. The student is asked to give her/his name and major. The student is then asked 4 questions and room is given on the form for the student to put comments. The student is then asked to rank the overall class as Excellent, Very Good, OK, Poor, or Very Poor. The form, known as the tangerine, green, or blue sheet, is used at the end of a class hour primarily to gain information from the students on their understanding of the class material covered for that day. In a large lecture room of 80-100 students, she hands out 8 Minute Manager sheets to volunteers at the beginning of class. At the end of class, these eight students complete the sheets and turn them in to the instructor. Students will only need to complete a form at most 4 or 5 times during the semester, so it is not a constant burden on the student to complete the form. The evaluations in this paper will refer to those used in a junior level statistics class for problem solving for engineering students. The primary majors represented in the course are Civil Engineering, Bioengineering, Industrial Engineering, Computer Systems Engineering, and Computer Science. The course is known as being tough and most students know that they do not like the course before they begin. For this reason, some of the students are taking this course the last semester of their undergraduate program.

The Minute Manager can be used for extra credit or demerits. Since the student name is given the instructor can keep track of how many times each student has completed a form. When the forms are given out at the beginning of the class, students, who habitually arrive late, may never be in class in time to volunteer to complete a form. It has generally been the attitude of the author that in teaching a course of this type, it is up to the student if he/she wants to come to 
Figure 1. Minute Manager Class Evaluation Form

$$
\text { IEE } 380 \text { Spring } 2009
$$

Name:

Major:

1. What was the most important thing that you learned today?

2. What did you like most about the class today?

3. Do you have any questions about the class today? Are there topics that are muddy?

4. Do you have any questions about the course?

5. Comments:

Please circle overall rating:

$1=$ Excellent $\quad 2=$ Very Good $\quad 3=$ OK $\quad 4=$ Poor $\quad 5=$ Very Poor

class. If the student can learn the class on their own, and turn in assignments and take tests, more power to them; however, the author has also noted over many years that very few students can do this. Since quite a few students were cutting class, the author tried taking attendance one semester, $50 \%$ of the time, randomly between Tuesday and Thursday. Also if students missed more than so many days, their overall score in the class was reduced. When almost all of the students have completed at least one evaluation, the names of students can be called out to have them complete an evaluation. Usually the student will be told by his friends that his name was called and he will attend the next class. The general conclusion of this experiment was that it did improve student attendance, but the students did not like the system. The author concluded that there was not enough positive benefit to continue to monitor attendance.

The Minute Manager sheets are now purely voluntary and students are told that if their overall score is on the bubble, then having completed 4 or 5 evaluations may help them over the bubble. A name is necessary on the form for the student to get credit for turning in the evaluation. Other than recording the date on a Minute Manager the author does not pay attention to the names, other than sometimes a question or a remark calls for a personal response. In this case, the student is sent an email to help resolve the issue. Having the major on the evaluation helps the instructor interpret some of the remarks and gives the remark some context.

Classes each have their own personality and some semesters almost all of the students will attend and other semesters the attendance may be very sporadic. This course is a 3 semester credit hour class with two 50-minute lectures and a two-hour lab each week taught by TAs. Some students cut class and expect to get all of the material in the lab session. We try to have the lab session do 
some review, but mostly to expand on the material by showing the students how to run the data on MiniTab. The students also take the opportunity on the Minute Manager to comment on how the labs are being conducted.

There are many ways in which a professor can handle the material that she receives from the Minute Manager. The professor can keep in touch with the class. The students will express what they understand and what they don't. They will express what they like and what they don't. They will complain and they will praise. By reading the Minute Manager sheets after class the professor has a general grading of the class for that day. The author has found that if the primary topics mentioned on the Minute Managers are read and talked about at the beginning of the next class and both complimentary and critical remarks are read and responded to, the instructor can keep quite close to their class. Corrections can be made, muddy topics cleared, and doubts dispelled. In general, the instructor evaluations at the end of the semester should not be a surprise.

It is assumed that if one person in the class has a particular question, probably 10 more have the same question. It is also assumed that students will give honest evaluations. It is assumed that the professor will read negative comments as well as positive comments, except for a negative comment about any particular student. A warning here: it takes a bit of a thick skin to read negative comments to the whole class. However, the rapport that a professor can gain with a class when they know that the professor is being honest with them makes the bit of pain worthwhile.

Many students like these Minute Managers. Often students will respond with "I like the orange sheets" when asked what they like about the class. Students comment that they like the review at the beginning of class while going over any questions on the material from the preceding class.. Sometimes student make a comment about a joke or show a sense of humor which is fun to share with the class. In the next sections comments from Minute Managers are given as examples.

\section{What is the Most Important Thing That You Learned Today?}

The first question on the Minute Manager is "What is the most important thing that you learned today?" The answer to this question is usually a very short summary of the main topic(s) of the day. Examples of this include:

- Why variance is squared

- That we have a table for F, how to use it

- That if it's two-sided you double the p-value

- That you can test the significance of a group of regressors and then test them individually to see if they add value or not

- A review of ANOVA

- What $\mathrm{R}^{2}$ is

- Overall review of regression, it helped put everything together

- Mostly review, but filling out the table was a good thing to review

- I actually learn what a designed experiment was instead of just knowing how to plug and chug

- Learning what $\mathrm{C}_{\mathrm{p}}$ was and how to measure it. Cool way of looking at statistical info. 
Another main topic for "the most important thing learned" is specific information on the course. Examples of this include:

- That we don't have to know much about the first chapter

- What this class consists of and what is expected

- What information is going to be on the midterm

- Information on the Capstone Project

Other topics have to do with their perception of the course. Examples include:

- Always look at the book or slides online before coming in the class. I looked at slides and it helped

- Central Limit Theorem is Awesome! Learn it. Know it. Love it.

- The regressions are finally starting to click; I think the repetition is helping out a lot.

Perhaps it would be helpful for the reader to know at this point that the author talks with the class at the beginning of the semester about how she knows that most of them are not overly excited about the course. However, she tells them, they are going to see some fantastic things during the semester and that some of them will actually learn to like the course by the end of the semester. She tells the students that she knows they won't admit to their friends that they like the course, but that some of them will be telling her that the course isn't that bad and yes, they may even enjoy the course! So when the author reads a comment about something being "Awesome!" the student may genuinely think so or may possibly just be repeating what the author said about the concept.

Sometimes the answer to "What was the most important thing that you learned today?" is more personal:

- To be on time.

- That my related major problems are with the book.

- For a CS major, it seems the course material has exceeded its relevance; however, it's still interesting.

- Where the class is. My best friend passed away last week.

\section{What did you like most about the class today?}

The second question is "What did you like most about the class today?" This question is really just a warm-up to the next question which is critical. This question allows the student to express if there was something about the class that they liked and want to have continued. It is also a time for a sense of humor. The following are some examples, first about how material is presented:

- Seeing how to put word problems into the different probability functions

- Review at the beginning of the class

- I always like how you go over the feedback results at the beginning of class.

- I liked the example problem.

- Class went a little slower today so it was easier to keep up and take notes.

- Going through all the examples 
- One part I really liked was Wednesday's lab. I have never seen MiniTab before and was very astonished about how simple and powerful it is. I wish I had it for previous classes.

- The practice problems at the end of class. I think they really help people understand the concepts more.

- Sample problems, always better than theory.

- You gave us information about the final!

- I liked all the examples done in class.

- More problems than explanations.

- The easy-to-understand Power Point

- The way the instructor went through everything for the problem

- The handout was very helpful; I was able to listen more to the theory instead of trying to keep up with all the writing on the board.

- Breaking down an example problem in steps as we did in problem 4.32 helped to better understand and follow the concepts.

- I like how we went over many examples in the book. I am a visual learner and it's nice to be able to see sample problems rather than just derive equations.

- I appreciate when you show the formula that is of interest for the day's topic-It helps me follow the hypothesis test. I also like when you diagram this material graphically... it makes so much more sense with a picture.

- Doing sample problems. I am not a fan of theory or where they come from, just how used.

- The problem at the beginning was a good way to introduce the topic.

This question may get statements of accomplishment:

- I finally understand what the p-value is

- I learned a lot

- I liked that you took the time to go over the same material from Chapter 7 again. It is much clearer this time around.

This question may also evoke some personal statements:

- Sense of humor

- The joke at the beginning (Once in a while a joke is good for a class)

- That it is over

- That the class was quiet

- It was very fun!

- Telling us about yourself. Very interesting. (Last class of semester)

- I liked the discussion on Master's Degrees (We faculty need to remember to do this each semester.)

- I am curious to see what we will learn about quality. (The author tells the students they will see some really neat stuff!) 


\section{Do You Have Any Questions about the Class Today? Are there topics that are muddy?}

The third question is "Do you have any questions about the class today? Are there topics that are muddy?" While the first two questions are useful and give good feedback, this question is the most important one. The question allows the student to tell what she does not understand. The answers to this question let the instructor know what material has not sunk in. After teaching a course several times, the instructor already knows where the students are likely to have the most problems understanding material. However, an instructor may believe that he has finally figured out the very best way to explain a particular concept and feel confident that most students now understand this concept. However, in the class evaluations the instructor may find two or three of the eight students that turned in the Minute Manager that day still having problems with the concept. The instructor can then alert the TA to cover this topic again in the lab that week and can also review the topic at the beginning of the next class. Here are some typical examples:

- What is the difference between $\mathrm{s}^{2}$ and $\sigma^{2}$ ?

- I didn't really understand the charts you showed from p. 269 in the book.

- How do we decide the alternative hypothesis?

- Where is the estimate of the variance in the ANOVA Table?

- Can we have more examples of residual that aren't indicative of a good model?

- This is the first time I have seen the stem and leaf concept as well as the box plot; therefore, I have questions on them.

- Don't understand the p-value

- How big does $\mathrm{p}$ need to be so that we stay with $\mathrm{H}_{\mathrm{o}}$ when no $\alpha$ is given?

- A little confused about what the contrast is

Other examples are of a different type:

- No, the class was clear.

- Seems like the class went extremely fast! Most do not have a book yet! (First day.)

- I need to catch up on the reading and then I'll have questions if something is still not clear.

- Think everything was explained very well!

- For the quizzes, should I feel safe if I'm near the class average or is that a danger zone?

- Why is the course material getting seemingly easier/simpler?

- Would you be able to look over reports before we turn them in?

\section{Do you have any questions about the course?}

"Do you have any questions about the course?" is the fourth question. The students also use this question for them to express questions, things they do not like, and also things about the course that they do like. Consider the following examples:

- Why can't review solutions be posted on line? (They are.) I would only take a picture with a digital camera then print it anyway.

- Is there a reason that the quizzes are worth more than the tests or the capstone project? 
- How can I see the readings as more of a simple task than an obstacle? The text is very dry, so I seem to become impatient with it....

- Is there going to be an opportunity to earn extra points?

- How can I use this information to help me with my major/I think that you already answered that question.

- What will the final be? (How long, format?)

- What will be covered in the quiz? (Always through the material covered the last week.)

- Will the grades be curved?

- How big is the curve; not sure I am passing this class.

- Will the topics that we skip be on the midterm?

- Why is the final curve for the class so small given the apparent difficulty of the quizzes and tests?

- Not at this time.

- None.

- No...everything was clear.

- Not muddy yet. (Hopeful optimism.)

- Keep doing things like you are; the course is fine.

\section{Comments}

This is the place on the Minute Manager where the student can let it all hang out. The students are sometimes quite critical and other times very complimentary. Here are some of the comments that the author has received:

- I learn more in labs than lecture, but the labs lag behind the lecture material, so I am generally confused. (We improved the lab material to keep it up with the lectures.)

- Forget theory, stick to the examples, please.

- If we had more theory we would know better what we are doing.

- I think this course covers too many topics rather than spending more time on each chapter and covering a little more theory.

- Quizzes are really tough. Each quiz feels like an exam! (It is.)

- I want this class to be over!

- I did all the problems in the recommended homework, but I still thought the quiz was completely different.

- The way the lab is structured right now just doesn't make much sense.

- You go too fast!

- Slow down.

- Can you write larger?

- Could you please go a bit slow on the slides so we could get enough time to copy? (Students are urged to download the slides, read them, and take them to class so they don't have to copy it.)

Some comments are mixed:

- Seems like this will be a fun class_-but could slow down. 
- A lot to study for class; you are a good professor. Really fast speed, zooming in and out of problems.

- Besides learning the main concepts of the chapters, this class is very repetitious, which is good because it gets easier the more I do it.

- Good job, lectures are improved from the beginning. (The beginning of the course is considered the hardest part.)

Some comments make teaching all worthwhile:

- Good class.

- I liked the slides style of teaching (PowerPoint) Creating PowerPoints for teaching is helpful

- Good lecture!

- I don't know anything about the Phoenix Suns, but it is fun to hear about them!

- I can tell you are very organized.

- Even though I can't say I actually like the readings (reading material before class), doing the readings really does help...maybe I should read in smaller page intervals. I UNDERSTOOD EVERYTHING!

- I thought that I would not like this course, but I can see that it is quite useful.

- I actually am beginning to like this course.

- Thanks for being a great teacher.

- Do you regularly teach any other I.E. courses? All in all, you are a great professor.

- I was asked in an interview if I knew how to use MiniTab, and I was able to say yes and got the job.

- Loved the lecture!

Some majors think that they should not have to take the course or at least not nearly as much of it:

- Engineers should have to take computer science, but computer science students shouldn't have to take engineering courses such as statistics.

- CE students should not have to take statistics.

- This course shouldn't cover as much material. We should only have to cover about 4 chapters (out of 8).

One of the author's favorite comments is this one:

- At the beginning of the semester this class was the one I liked the least. Now (near the end of the semester) it is my favorite. Before you get too happy, my other choices are circuits and thermo!

\section{Discussion and Conclusions}

Most of the students like the use of the Minute Manager, especially since the questions on the sheets provide the review topics for the next class period. It is something of a challenge for the instructor to not spend too much time on the questions and comments. A few students have expressed their belief that because the sheets are not anonymous, the students are just browning 
up and writing what the professor wants to hear. This may be true, but there are enough negative comments to keep it close to honest. In some cases, the question is quite personal and calls for a personal answer. With the name on the comment sheet, the instructor can then email the student and try to resolve a situation immediately.

When the Minute Manager sheets are handed out at the beginning of a class, the names of the students are not noted. If a student did not turn in the sheet at the end of the hour, the author would not know which student did not turn in the form. Only a very few (1-3 per semester) students do not turn in the completed form after the class. The class rating from 1 to 5 is interesting to consider. Some students do not mark this part of the form. Some students are very stingy with a rating: the comment may say "Good class" and the rating given is OK. Usually at least two or three students will rate the class as "excellent."

The types of answers on the evaluation sheets were discussed as well as how the professor can use these questions and comments to better understand where the class is on the current topic and what, if anything, can be done to help the students. An important facet of this process is that the professor needs to be honest with the class and discuss critical remarks as well as complimentary remarks about the class. The author does write fast and sometimes will think that the lecture was a good pace only to see a comment for that day that a student considered it too fast. The Minute Manager is a good reminder to slow down.

The author has used this system for every class and also for academic success workshops for many years. The author likes to be personable with a class and also to have some fun in the classroom. Using the Minute Manager keeps her in touch with the class and most students appreciate the honest way in which she goes through the comments in class, both good and bad!

References

1. Brent, R. and Felder,R.M., "Helping Faculty Get Off to a Good Start," 2000 ASEE Annual Meeting Proceedings, ASEE, June 2000, 7 pages.

2. Boice, R., The New Faculty Member. San Francisco: Jossey-Bass, 1992. See also R. Boice, Advice for New Faculty Members, Needham Heights, MA, Allyn \& Bacon, 2000.

3. Angelo, T.A. and Cross, K.P., "Classroom Assessment Techniques: A Handbook for College Teaching $\left(2^{\text {nd }}\right.$ ed.) San Francisco: Josey-Bass, 1993.

4. Felder, R.M., "Teaching Teachers to Teach: The Case for Mentoring," Chemical Engineering Education, 27(2), 176-177, 1993. Available on-line at http://www2.ncsu.edu/effective teaching/ .

5. Brent, R., Felder, R.M., Rajala, S.A., Gilligan, J.G., and Lee, G., "New Faculty 101: An Orientation to the Profession", ASEE/IEEE Frontiers in Education Conference, Reno, NV, October 2001, 3 pages.

6. Brent, R., Felder, F., and Rajala, S., "Preparing New Faculty Members to be successful: A No-Brainer and Yet a Radical Concept," Proceedings of the 2006 American Society for Engineering Education Annual Conference, Chicago, IL, October 2006, 14 pages.

7. Gavrin, A., Watt, J. X., Marrs, K., and Blake, R.E. Jr., "Just-in-Time Teaching (JiTT): Using the Web to enhance Classroom Learning," Proceedings of the 2003 American Society for Engineering Education Annual Conference, Nashville, TN, October 2003, 13 pages.

8. Smith, K.A., Morgan, J., Ledlow, S., Imbrie, P.K., and Froyd, J., "Engaging Faculty in Active/Cooperative Learning," ASEE/IEEE Frontiers in Education Conference, Boulder, CO, November 2003.

9. Courter, S.S., Freitag, C., and McEniry, M., "Ways of Knowing: Ways of Practice," ASEE/IEEE Frontiers in Education Conference, Boulder, CO, November 2003. 
10. Mitchell, J. E., "Time Professors Spend Improving their Teaching," ASEE/IEEE Frontiers in Education Conference, Savannah, GA, October 2004, S1C-6 - S1C-8.

11. Miller, R.L., Streveler, R. A., Nelson, M. A., Geist, M. R., and Olds, B. M., "Concept Inventories Meet Cognitive Psychology: Using Beta Testing as s Mechanism for Identifying Student Misconceptions," Proceedings of the 2005 American Society for Engineering Education Annual Conference, Portland, OR, October 2005, 18 pages.

12. Davis, J.S., "Strategic Planning for New Faculty: From What to How," Proceedings of the 2005 American Society for Engineering Education Annual Conference, Portland, OR, October 2005, 9 pages.

13. Minerick, A.R. and Keith, J.M., "Culture Shock: Acclimating as a New Faculty Member," Proceedings of the 2005 American Society for Engineering Education Annual Conference, Portland, OR, October 2005, 12 pages.

14. Felder, R.M., and Silverman, L.K., "Learning and Teaching Styles in Engineering Education," Engineering Education, 78(7), 1988, 674-681.

15. Litzinger, T.A., Lee, S.H., Wise, J.C. and Felder, R.M., "A Study of the Reliability and Validity of the Felder-Solomon Index of Learning Styles, Proceedings of the 2005 American Society for Engineering Education Annual Conference, Portland, OR, October 2005, 16 pages.

16. Aghayere, A., Use of Ongoing Assessment of Intended Learning Outcomes to Evaluate Effectiveness of Online and Oncampus Delivery of a Structural Analysis Course," Proceedings of the 2004 American Society for Engineering Education Annual Conference, Salt Lake City, UT, October 2004.

17. Aghayere, A., "The Case for Ongoing Course Assessment," Proceedings of the 2005 American Society for Engineering Education Annual Conference, Portland, OR, October 2005.

18. Aghayere, A., "The Efficacy of Ongoing Course Assessment for Enhancing Student Learning in Structural Design Classes," Proceedings of the 2006 American Society for Engineering Education Annual Conference, Chicago, IL, October 2006, 13 pages.

19. Barr, R.E., Kruedger, T.J., and Aanstoos, T. A., "Continuous Outcomes Assessment in an Introduction to Mechanical Engineering Course," ASEE/IEEE Frontiers in Education Conference, San Diego, CA, October 2006, S1E-9 - S1E-14.

20. Finelli, C., Gottfried, A., Kaplan, M., Mesa, V., O’Neal, C., and Piontek, M., "Evaluating Methods to Improve Teaching in Engineering," Proceedings of the 2006 American Society for Engineering Education Annual Conference, Chicago, IL, October 2006, 20 pages.

21. Jugdev, K., "Advice for New Engineering Faculty: Insights Gained from Faculty Development Programs," Proceedings of the 2007 American Society for Engineering Education Annual Conference, Honolulu, HI, October 2007, 10 pages.

22. Britos, P., Rey, E.J., Rodriguez, D., and Garcia-Martinez, R., "Work in Progress - Programming Misunderstandings Discovering Process Based on Intelligent Data Mining Tools," ASEE/IEEE Frontiers in Education Conference, Saratoga Springs, NY, October 2008, F4H-1 - F4H-2. 